Gut, 1987, 28, S1, 221-226

\title{
Proliferative effects of 'fibre' on the intestinal epithelium: relationship to gastrin, enteroglucagon and PYY
}

\author{
R A GOODLAD, W LENTON, M A GHATEI, T E ADRIAN, S R BLOOM, \\ AND N A WRIGHT \\ From the Cancer Research Campaign Cell Proliferation Unit, Departments of Histopathology, and Medicine, \\ Royal Postgraduate Medical School, Hammersmith Hospital, London
}

SUMMARY Refeeding starved rats with a fibre free 'elemental' diet increased crypt cell production rate (CCPR) in the proximal small intestine but not in the distal regions of the gut. Little effect on CCPR was seen when inert bulk (kaolin) was added to the 'elemental' diet. Addition of a poorly fermentable dietary 'fibre' (purified wood cellulose) had little effect on intestinal epithelial cell proliferation except in the distal colon where it significantly increased CCPR. A more readily fermentable 'fibre' (purified wheat bran) caused a large proliferative response in the proximal, mid and distal colon and in the distal small intestine. A gel forming 'fibre' also stimulated proliferation in the distal colon. There was no significant correlation between CCPR and plasma gastrin concentrations, but plasma enteroglucagon concentrations were significantly correlated with CCPR in almost all the sites studied. Plasma PYY concentrations also showed some correlation with CCPR, especially in the colon. Thus, whilst inert bulk cannot stimulate colonic epithelial cell proliferation, fermentable 'fibre' is capable of stimulating proliferation in the colon, and especially in the distal colon: it can also stimulate proliferation in the distal small intestine and it is likely that plasma enteroglucagon may have a role to play in this process.

Low bulk, chemically defined semisynthetic (elemental) diets cause atrophy and reduced intestinal cell proliferation. ${ }^{1-4}$ This has been attributed to lack of non-absorbable bulk, ${ }^{5}$ but more recent work suggests that it may be because of lack of dietary fibre.$^{6-8}$ We have shown that while inert bulk(kaolin) can prevent atrophy of colonic muscle in mice fed an elemental diet, it cannot restore crypt cell production or cell population to the levels seen in mice fed a standard diet; however, cellulose could restore both cell production and cell populations to 'normal' levels.' The term 'dietary fibre' encompasses a wide range of diverse substances which cannot be digested without the action of the gut microflora. ${ }^{10}$ The proliferative effects of the various types of 'fibre' also appear to vary, ${ }^{8}$ this may be because of differences in the ease with which they can be fermented in the hind gut, as there is evidence that the products of hind gut

Address for correspondence: Dr RA Goodlad, Dept of Histopathology, Royal Postgraduate Medical School, Hammersmith Hospital, Ducane Road, London W12 0HS fermentation can have a trophic effect on the gastrointestinal epithelium. ${ }^{11} 12$ Such an effect could be direct or indirect, and if the latter, a hormonal mechanism may be implicated. Enteroglucagon and gastrin are two of the hormones which have most often been implicated in the control of intestinal epithelial cell proliferation. ${ }^{13}$

The hypothesis that hind gut fermentation stimulates colonic epithelial cell proliferation was tested in the present study by comparing the effects on the intestinal epithelium of refeeding starved rats with an elemental diet supplemented with inert bulk (kaolin), a poorly digestible fibre (wood cellulose), a digestible bran concentrate (Trifyba) and a soluble non-starch polysaccharide which forms a gel in water (prepared from the Ispaghula husk). Refeeding with the elemental diet alone or with a standard rat chow was also studied. The proliferative rates of the above treatments were also compared with the plasma hormone concentrations of gastrin, enteroglucagon and peptide YY (PYY), a new candidate 
hormone ${ }^{14}$ which appears to be colocalised with enteroglucagon. ${ }^{15-17}$

\section{Methods}

ANIMALS

Male Wistar rats were used (Olac Ltd, Blackthorn, Oxon, UK). They were kept in wire bottomed cages and fed a powdered version of a standard laboratory diet (Labshure PRD, Christopher Hill, Poole, Dorset) for two weeks before the start of the experiment and were then fed or starved as described. They had constant access to water.

The rats were divided into eight groups (of 10) as follows,

Group $A=$ Fed group (powdered laboratory rat diet).

Group B $=$ Starved for three days.

Group C $=$ Starved (three days) then refed (two days - Flexical + kaolin)

Group $\mathrm{D}=$ Starved (three days) then refed (two days - Flexical + wood cellulose)

Group E = Starved (three days) then refed (two days - Flexical + Trifyba)

Group $F=$ Starved (three days) then refed (two days - Flexical + Ispaghula mucilage)

Group $\mathrm{G}=$ Starved (three days) then refed (two days - Powdered standard diet)

Group $\mathbf{H}=$ Starved (three days) then refed (two days - Flexical)

All refed groups were given $15 \mathrm{~g} / \mathrm{rat} /$ day of their respective diets at 0900 hours. The 'elemental' diet Flexical was from Mead Johnson, Slough. The cellulose was Solka Floc grade BW-100 (Johnsen Jorgensen \& Wettre Ltd, London). Trifyba is a fibrous extract of wheat grain (Labaz Sanofi UK Ltd, Wythenshawe, Manchester; hemicellulose $40 \%$, cellulose $20 \%$, lignin $15 \%$ and pectin $5 \%$ ). Ispaghula is a dietary mucilage prepared from the Ispaghula husk ${ }^{18}$ (Reckitt \& Colman, Hull).

Rats were given an intraperitoneal injection of vincristine sulphate (Tillots Laboratories, Henlow, Bedfordshire, UK) at 0900 hours and were killed at timed intervals 30 to 180 minutes later. Samples of intestine were fixed in Carnoy's fluid. The tissue was later stained with the Feulgen reaction and the intestinal crypts displayed by microdissection; the number of arrested metaphases in 10 crypts was then counted and the mean values plotted against time after injection. The slope of the line, fitted by least squares linear regression, gave the CCPR. ${ }^{19}$ Gut hormones were measured using previously described radioimmunoassays for gastrin, ${ }^{20}$ pancreatic glucagon, ${ }^{21}$ enteroglucagon ${ }^{22}$ and PYY ${ }^{23}$ Enteroglucagon was calculated by subtracting specifically measured pancreatic glucagon from total $\mathrm{N}$-terminal glucagon immunoreactivity.

\section{Results}

There were no significant differences between the start weights, weights of starvation and the per cent weight losses. The mean weight loss (g) for all the groups after three days starvation was $20.1 \% \pm 0.4 \%$. All groups except group D (Flexical + wood cellulose) showed a modest increase in body weight upon refeeding and the weight increase of group $\mathrm{H}$ (Flexical) was significantly $(p<0.001)$ greater than that of the other groups.

The CCPRs of the sites studied in the intestine are shown in Figures 1, and 2. Starvation significantly decreased CCPR in all sites $(p<0.001)$ except for the mid colon where $\mathrm{p}<0.05$.

Refeeding led to a general increase in CCPR, and diet $E$ had by far the most pronounced effect.

The CCPRs of the refed groups were still significantly lower than that of the fed group at all sites in the small intestine, except group E at the $75 \%$ SI site. The colons of the refed groups had more sites with CCPRs which approached fed levels and the fermentable fibres had the greatest effect, especially in the distal colon.

The effect of the various treatments on plasma enteroglucagon, gastrin and PYY are shown in Fig 3. Starvation significantly lowered the plasma levels of all hormones $(p<0.001)$. Analysis of variance showed that plasma gastrin concentrations were not significantly altered after refeeding. Plasma enteroglucagon increased significantly after refeeding in all groups except group C (Flexical + Kaolin) (where $\mathrm{p}<0.055$ ), and there were significant differences between the enteroglucagon levels of the refed groups $(p<0.01)$. Plasma concentrations of PYY also showed significant $(p<0.001)$ differences between the refed groups, mainly because of there being a marked increase in PYY concentrations in groups refed with Flexical + Trifyba or Ispaghula ( $E$ and $F)$.

Pearsons product moment correlation showed significant correlations between CCPR and plasma enteroglucagon in four sites $(p<0.001$ to $p<0.02)$ and between CCPR and plasma PYY in four sites $(p<0.01)$ and between CCPR and gastrin in three sites $(p<0.05)$; however, these correlations were unduly influenced by the high CCPRs and hormone levels in group A (fed). Spearmans rank correlation was thus used to reduce this bias (Table). Plasma enteroglucagon concentrations were significantly correlated with the CCPRs of all sites except the mid colon. Plasma PYY concentrations were significantly correlated with the CCPR in three sites, two of these 


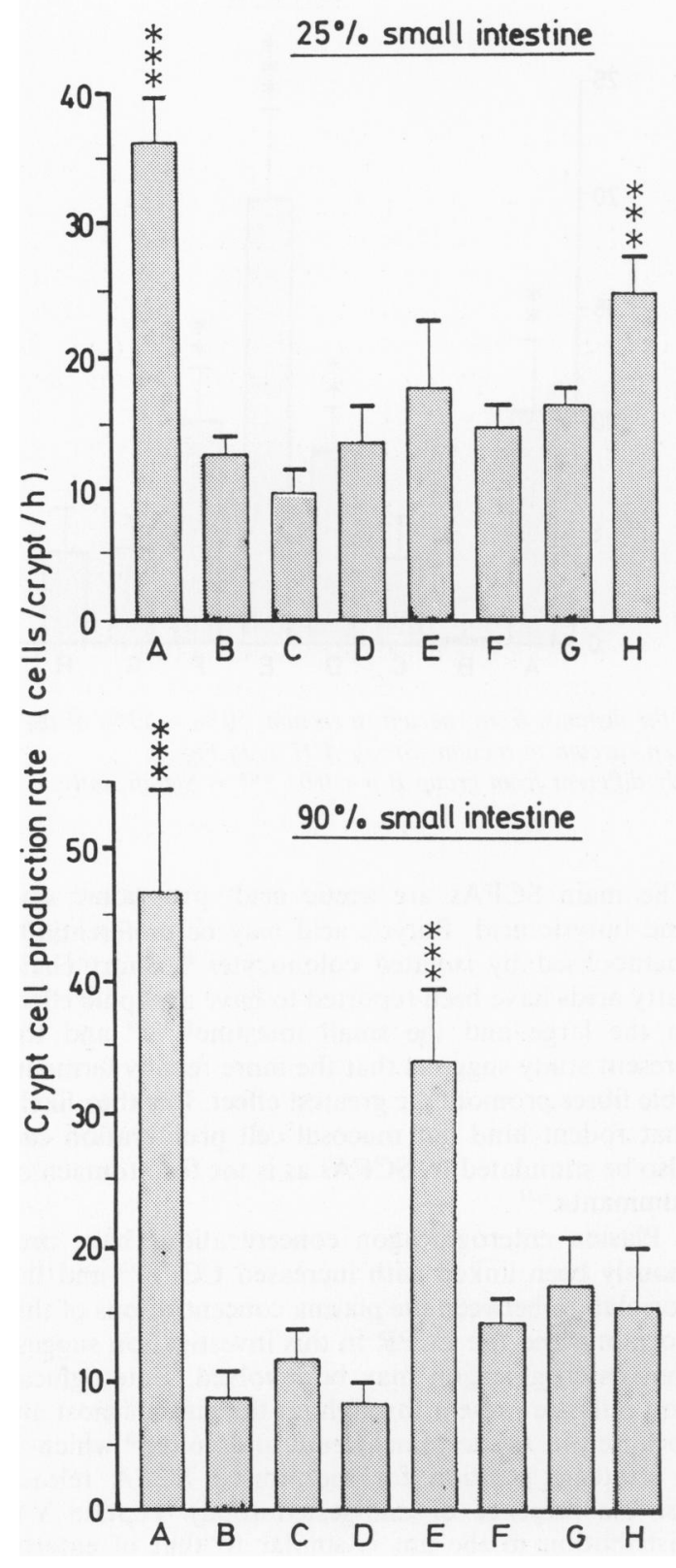

being in the colon. There was no significant correlation between plasma gastrin concentrations and CCPR or between plasma gastrin concentration and enteroglucagon or PYY ( $r s=0 \cdot 190,0 \cdot 286)$. Plasma PYY was, however, significantly correlated with enteroglucagon $(r s=0.905, p<0.01)$.

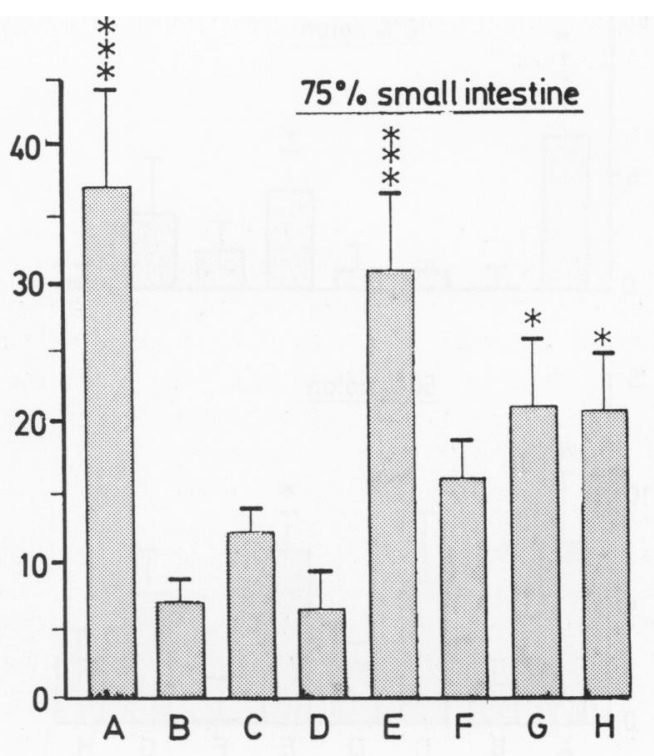

Fig. 1. Crypt cell production rates in the small intestine $25 \%=25 \%$ of the distance from pylorus to ileocaecal valve. $75 \%=75 \%$ of the distance from pylorus to ileocaecal valve. $90 \%=90 \%$ of the distance from pylorus to ileocaecal valve. Groups $A=F e d$ group (powdered laboratory rat diet) $B=$ Starved for 3 days, $C=$ Starved then refed - Flexical + kaolin, $D=$ Starved then refed - Flexical + wood cellulose, $E=$ Starved then refed - Flexical + Trifyba, $F=$ Starved then refed Flexical + Isphagula mucilage, $G=$ Starved then refed Powdered standard diet, $H=$ Starved then refed-Flexical.

* = significantly different from group $B p<0.05$

** = significantly different from group $B p<0.01$ $* * *=$ significantly different from group $B p<0.001$

\section{Discussion}

The results of the present study show that a low residue 'elemental' diet is capable of stimulating an adaptive response after refeeding, and confirms that the effects of such diets are mainly confined to the 

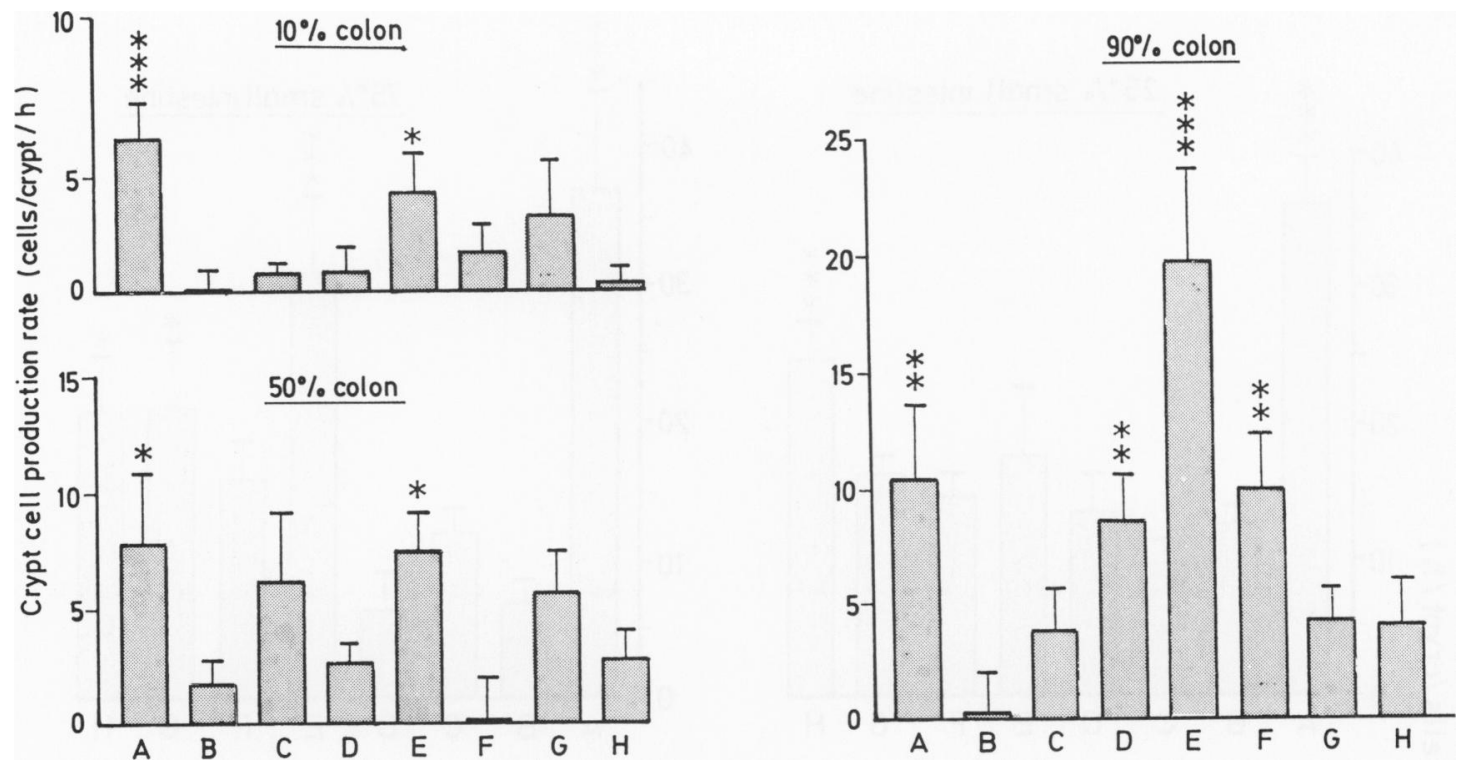

Fig 2. Crypt cell production rates in the colon $10 \%=10 \%$ of the distance from caecum to rectum. $50 \%=50 \%$ of the distance from caecum to rectum. $90 \%=90 \%$ of the distance from caecum to rectum. Group $A-H$ as in Fig. 1 .

${ }^{*}=$ significantly different from group $B$ p $<0.05^{* *}=$ significantly different from group $B p<0.01^{* * *}=$ Significantly different from group $B$ p $<0.001$

proximal regions of the gastrointestinal tract. The diminished proliferative response seen in the distal gut, which occurred despite the considerably greater calorific value of this diet confirms that such diets deprive the distal gut of luminal nutrition and/or functional demand.

The addition of kaolin to the elemental diet had little effect on CCPR confirming that bulk has little effect on mucosal proliferation. ${ }^{9}$ Flexical + wood cellulose had a significant effect on the CCPR of the distal colon despite the poor digestibility of this fibre compared with the more natural bran like fibres. ${ }^{10}$ Addition of the purified wheat bran fibre 'Trifyba' had a dramatic stimulatory effect on the CCPR at almost all sites. This was most pronounced in the distal colon.

Dietary fibre has several effects on the bowel, all of which may affect carcinogenesis. Fibre can delay gastric emptying and impede or delay absorption, alter transit times, dilute or bind carcinogens, alter bile acid levels and cholesterol levels and induce xenobiotic metabolising enzymes. ${ }^{24}$ Hind gut fermentation plays an important role in the energy balance of most single stomached mammals including man, ${ }^{25}$ and the products of this fermentation are the short chain fatty acids (SCFAs) or volatile fatty acids (VFAs). The release of these SCFAs also has several effects on the colon such as lowering the luminal $\mathrm{pH}$, increasing mucosal blood flow, altering ammonia concentrations and increasing water absorption. ${ }^{26-28}$
The main SCFAs are acetic acid, proprionic acid and butyric acid. Butyric acid may be preferentially metabolised by isolated colonocytes. ${ }^{29}$ Short chain fatty acids have been reported to have a trophic effect in the large and the small intestine ${ }^{11230}$ and the present study suggests that the more readily fermentable fibres promote the greatest effect. It is thus likely that rodent hind gut mucosal cell proliferation can also be stimulated by SCFAs as is the forestomach of ruminants. ${ }^{631}$

Plasma enteroglucagon concentrations have previously been linked with increased CCPR ${ }^{13}$ and the correlation between the plasma concentrations of this hormone and the CCPR in this investigation suggest that enteroglucagon may be involved. Enteroglucagon cells are present throughout the gut but most are localised in the terminal ileum and colon ${ }^{32}$ which is a strategic position for monitoring SCFA release (or the presence of undigested food). Peptide YY distribution in the gut is similar to that of enteroglucagon ${ }^{131617}$ and it is interesting that most of the correlation between PYY and CCPR was caused by high levels of PYY in groups $E$ and $F$ which had the most readily fermented diets and that $2 / 3$ of the PYY correlations observed occurred in the colon. Peptide YY can inhibit gastric acid secretion and stomach emptying ${ }^{33}{ }^{34}$ thus active fermentation in the colon may be a signal for delaying gastric digestion and emptying mediated via PYY. A role for PYY in the control of gastrointestinal epithelial cell pro- 

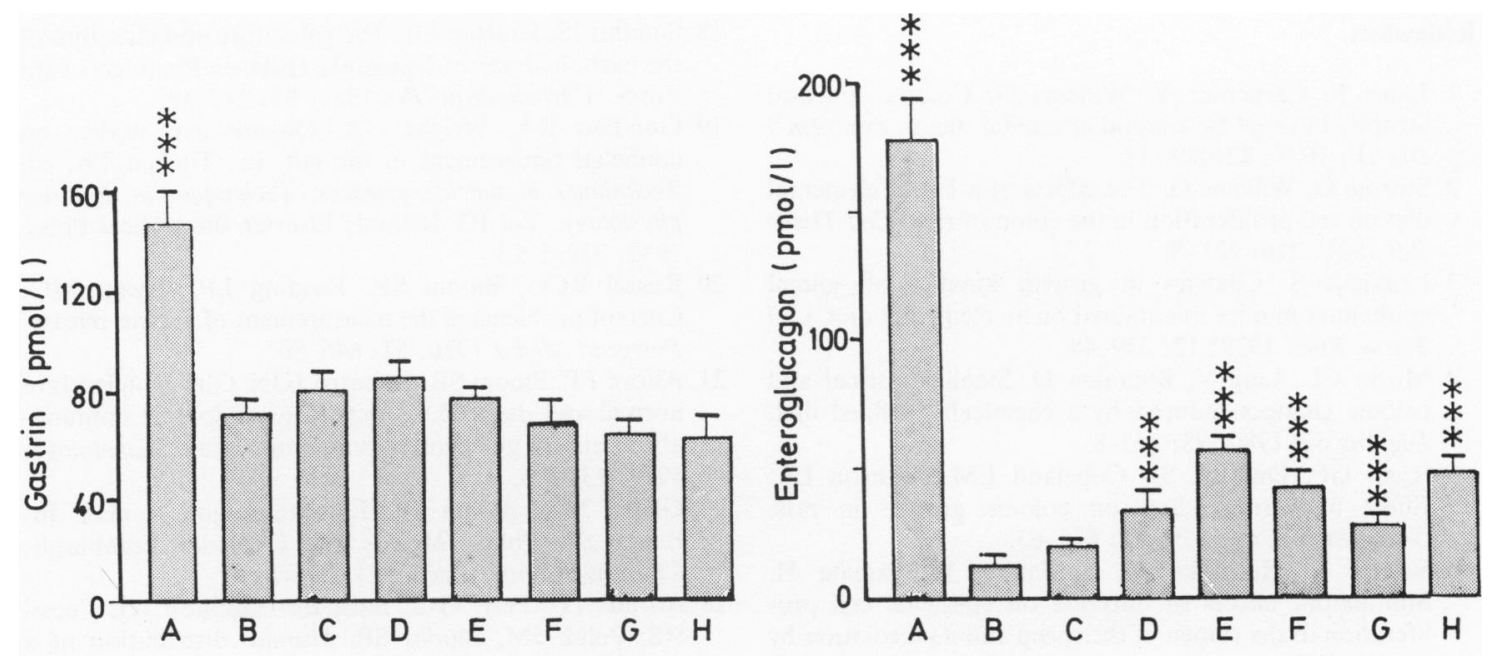

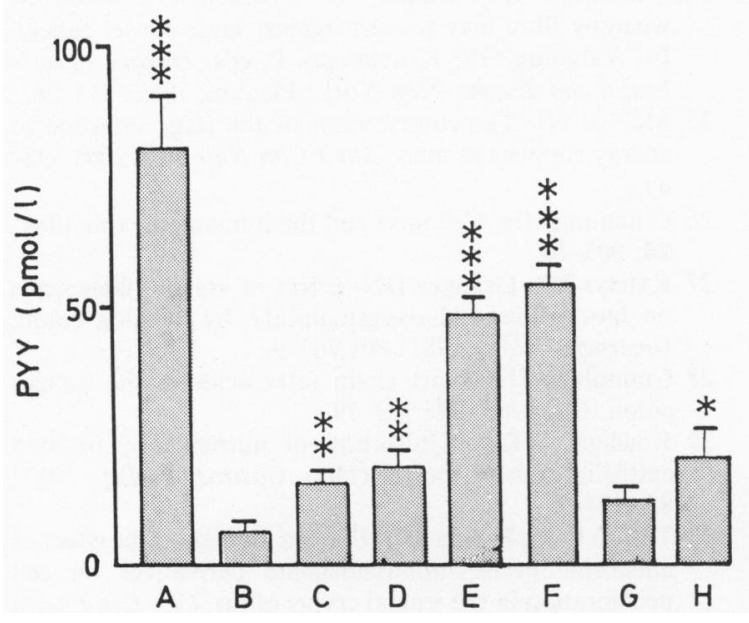

Table Spearmans rank correlation coefficient for crypt cell production rates and plasma hormone levels.

\begin{tabular}{llrl}
\hline & $\begin{array}{l}\text { Plasma } \\
\text { Enteroglucagon }\end{array}$ & $\begin{array}{l}\text { Plasma } \\
\text { Gastrin }\end{array}$ & $\begin{array}{l}\text { Plasma } \\
P Y Y\end{array}$ \\
\hline 25\% small intestine & $0.881^{*}$ & -0.095 & $0.667 \dagger$ \\
$75 \%$ small intestine & $0.738 \dagger$ & -0.024 & 0.571 \\
$90 \%$ small intestine & $0.738 \dagger$ & -0.024 & 0.571 \\
$10 \%$ colon & $0.690 \dagger$ & 0.381 & $0.643 \dagger$ \\
$50 \%$ colon & 0.500 & 0.452 & 0.310 \\
$90 \%$ colon & $0.833^{*}$ & 0.333 & $0.810 \dagger$ \\
\hline
\end{tabular}

$*=p<0.01 ; \dagger=p<0.05$.

liferation is less certain as although PYY levels have been shown to correlate with CCPR in resected rats, direct infusion of PYY has little effect on CCPR. ${ }^{35}$

The conclusions of the present study are thus; that while a fibre free diet can stimulate epithelial cell proliferation in the proximal small intestine of refed rats, cell proliferation in the distal gut and colon requires other factors. The hypothesis that inert 'bulk' is required is not borne out. Readily fermentable 'fibre' can be effective in stimulating proliferation and the release of SCFAs into the lumen could account for the proliferation effects noted. These proliferative effects were also noted in the small intestine and plasma enteroglucagon may be implicated in this response.

We are pleased to acknowledge the financial assistance of the Cancer Research Campaign. We thank Reckitt \& Colman for the Ispaghula gel, Labaz Sanofi UK Ltd for the Trifyba and Johnsen Jorgensen \& Wettre for the Solka Floc. 


\section{References}

1 Janne P, Carpenter Y, Willems G. Colonic mucosal atrophy induced by a liquid elemental diet in rats. Am J Dig Dis 1977; 22: 808-12.

2 Storme G, Willems G. The effects of a liquid elemental diet on cell proliferation in the colon of rats. Cell Tissue Res 1981; 216: 221-5.

3 Leahnert $S$. Changes in growth kinetics of jejunal epithelium in mice maintained on an elemental diet. Cell Tissue Kinet 1979; 12: 239-48.

4 Morin CL, Ling V, Bourassa D. Small intestinal and colonic changes induced by a chemically defined diet. Dig Dis Sci 1980; 25: 123-8.

5 Ryan GP, Dudrick SJ, Copeland EM, Johnson LR. Effect of various diets on colonic growth in rats. Gastroenterology 1979; 77: 658-63.

6 Sakata T, Hikosaka K, Shiomura Y, Tamate H. Stimulatory effects of butyrate on epithelial cell proliferation in the rumen of the sheep and its mediation by insulin. Differences between in vivo and in vitro studies. In: Appleton DR, Sunter JP, Watson AC, eds. Cell proliferation in the gastrointestinal tract. Bath: Pitman Press, 1980: 123-37.

7 Tasmanjones C, Owen RL, Jones AL. Semipurified dietary fibre and small bowel morphometry in rats. Dig Dis Sci 1982; 27: 519-24.

8 Jacobs LR, Lupton JR. Effects of dietary fibres on rat large bowel mucosal growth and cell proliferation. Am J Physiol 1984; 246: G378-85.

9 Goodlad RA, Wright NA. Effects of addition of kaolin or cellulose to an elemental diet on intestinal cell proliferation in the mouse. Br J Nutr 1983; 50: 91-8.

10 Van Soest PJ. Some physical characteristics of dietary fibre and their influences on microbial ecology of the human colon. Proc Nutr Soc 1984; 43: 25-33.

11 Sakata T. Short chain fatty acids as the luminal trophic factor. Can J Anim Sci 1984; 64: 189-90.

12 Sakata T, Yajima T. Influence of short chain fatty acids on the epithelial cell division of digestive tract. $Q J \operatorname{Exp}$ Physiol 1984; 69: 639-48.

13 Wright NA, Alison M. The control of cell proliferation in the gastrointestinal tract. In: The biology of epithelial cell populations. Vol 2. Oxford: Clarendon Press, 1984: 842-67.

14 Tatemoto K, Mutt V. Isolation of two novel candidate hormones using a chemical method for finding naturally occurring polypeptides. Nature $1980 ; 285$ : 417-8.

15 El-Salhy M, Wilander E, Juntti-Berggren L, Grimelius L. The distribution and ontogeny of polypeptide YY (PYY) and pancreatic polypeptide (PP)-immunoreactive cells in the gastrointestinal tract of rat. Histochemistry $1983 ; 78$ : 53-60.

16 Ali-Rachedi, Varndell IM, Adrian TE, et al. Peptide YY (PYY) immunoreactivity is co-stored with glucagonrelated immunoreactants in endocrine cells of the gut and pancreas. Histochemistry $1984 ; 80$ : 487-91.

17 El-Salhy M, Grimelius L, Wilander E, Ryberg B, Terenius L, Lundberg JM, Tatemoto $\mathbf{K}$. Immunocytochemical identification of polypeptide YY (PYY) cells in the human gastrointestinal tract. Histochemistry 1983; 77: 15-23.
18 Sandhu JS, Hudson GJ. The gel nature and structure of the carbohydrate of Ispaghula Husk ex Plantago ovato Forsk. Carbohydrate Res 1981; 93 : 247-59.

19 Goodlad RA, Wright NA. Quantitative studies on epithelial replacement in the gut. In: Titchen TA, ed. Techniques in the life sciences. Techniques in digestive physiology. Vol P2. Ireland: Elsevier Biomedical Press, 1982: 212/1-23.

20 Russel RCG, Bloom SR, Fielding LP, Bryant MG. Current problems in the measurement of gastrin release. Postgrad Med J 1976; 52: 645-50.

21 Alford FP, Bloom SR, Nabarro JDN. Glucagon levels in normal and diabetic subjects. Use of specific immunoabsorbent for glucagon radioimmunoassay. Diabetologia 1977; 13: 1-6.

22 Ghatei MA, Bloom SR. Enteroglucagon in man. In: Bloom SR, Polak JM, eds. Gut hormones. Edinburgh: Churchill Livingstone, 1981: 332-8.

23 Adrian TE, Ferri G-L, Bacarese-Hamilton AJ, Fuessl HS, Polak JM, Bloom SR. Human distribution of a putative new gut hormone, peptide YY. Gastroenterology 1985; 89: 1070-77.

14 Cummings JH, Branch WJ. Postulated mechanisms whereby fibre may protect against large bowel cancer. In: Vahouny GV, Kritchevsky P, eds. Dietary fibre in health and disease. New York: Plenum, 1982: 313-26.

$25 \mathrm{McNeil}$ NI. The contribution of the large intestine to energy supplies in man. Am J Clin Nutr 1984; 39: 33842.

26 Cummings JH. Cellulose and the human gut. Gut 1984; 24: 805-10.

27 Kvietys PR, Granger DN. Effect of volatile fatty acids on blood flow and oxygen uptake by the dog colon. Gastroenterology 1981; 80: 962-9.

28 Cummings JH. Short chain fatty acids in the human colon. Gut 1981; 22 : 763-79.

29 Roediger WEW. Utilization of nutrients by isolated epithelial cells of the rat colon. Gastroenterology 1982; 83: 424-9.

30 Tutton PJM, Barkla DH. Further studies on the effect of adenosine cyclic monophosphate derivatives on cell proliferation in the jejunal crypts of rat. Clin Exp Pharm Physiol 1982; 9: 671-4.

31 Flatt WP, Warner RG, Loosli JK. Influence of purified materials on the development of the ruminant stomach. J Dairy Sci 1958; 41: 1593-600.

32 Bloom SR. Gut and brain - endocrine connections. $J R$ Coll Physicians Lond 1980; 14: 51-7.

33 Sukuki T, Nakaya M, Itoh Z, Tatemoto K, Mutt V. Inhibition of interdigestive contractile activity in the stomach by peptide YY in Heidenhain pouch dogs. Gastroenterology 1983; 85: 114-21.

34 Allen JM, Fitzpatrick ML, Yeats JC, Darcy K, Adrian TE, Bloom SR. Effects of peptide YY and neuropeptide $\mathrm{Y}$ on gastric emptying in man. Digestion 1984; 30: 255 62.

35 Savage A, Gornacz GE, Adrian TE, Goodlad RA, Wright NA, Bloom SR. Elevation of PYY following intestinal resection in the rat is not responsible for the adaptive response. Gut 1985; 26: 1353-8. 